\title{
ACOUSTIC RESPONSE OF AMAZON SHELF MUDDY SEDIMENTS
}

\author{
Pedro Smith Menandro ${ }^{1}$, Alex Cardoso Bastos ${ }^{1}$, Valéria da Silva Quaresma ${ }^{1}$ and Susana Beatriz Vinzón ${ }^{2}$
}

\begin{abstract}
Understanding the behaviour of acoustic signals in marine sediments is of great importance for applied coastal studies. In areas with high suspended sediment concentration, the detection and delineation of these fluid mud layers are imperative for the determination of nautical depths (navigability) and dredging projects. Herein, we investigate the response of the acoustic signal according to the frequency and surface sediments characteristics (grain size and density). The dataset was collected along the Amazon inner shelf (North Brazil), including high-frequency acoustic data (3.5, 33 and $210 \mathrm{kHz}$ ), surface sediment physical properties, in situ bottom density and suspended particulate matter derived from optical backscatter sensors. Results show a cross-shelf transition from a sandy to a muddy bottom, followed by a decrease in sediment seabed density. Acoustic data also show this transition, illustrated by different levels of signal penetration. Statistical analysis relating the geophysical records and the physical properties of the sediments showed that density was a determining variable for the interpretation of surface acoustic reflection. The acoustic sources were able to detect the occurrence of fluid mud layers but the optical backscatter sensor had the best resolution in delineating the upper boundary of the fluid mud layer. The sub-bottom profiler $(3.5 \mathrm{kHz})$ detected the fluid mud layers, whereas the echo displacement were not always related to the presence of fluid mud. Finally, the results pointed out that for coastal engineering projects and navigation purposes, the mapping of seabed density along with geophysical surveys is effective, and highlighted the issue about delineation of upper fluid mud boundary.
\end{abstract}

Keywords: geoacoustic, fluid mud, Amazon River.

RESUMO. Fundamental para estudos aplicados a regiões costeiras, a geoacústica submarina auxilia na compreensão do comportamento do sinal acústico no sedimento marinho. A detecção de depósitos lamosos em registros acústicos de alta resolução é de fácil distinção, aparecendo normalmente como pacotes sedimentares de baixa reflexão. Em áreas com alta concentração de material particulado em suspensão, a detecção e a delimitação dessas camadas de lama fluida são fundamentais para a determinação da profundidade náutica e para realização de projetos de dragagem. Esse estudo tem como principal objetivo investigar variações no sinal acústico de diferentes fontes, de acordo com a frequência e as características do sedimento superficial (granulometria e densidade). A base de dados analisada foi coletada na Plataforma Interna do Canal Norte do Rio Amazonas, e é composta por registros geofísicos de alta frequência (3,5, 33, $210 \mathrm{kHz})$, propriedades físicas do sedimento superficial, densimetria in situ e medidas de material particulado em suspensão. Os resultados sedimentológicos e geofísicos mostram uma transição de um fundo arenoso para lamoso na plataforma continental, acompanhada por uma diminuição na densidade do sedimento superficial do fundo marinho. A análise estatística apontou a densidade como variável determinante para interpretação da reflexão superficial do sinal acústico. As fontes acústicas foram capazes de detectar a ocorrência da lama de fluida, mas o sensor óptico obteve a melhor resolução para delinear o limite superior da camada de lama fluida. 0 perfilador de sub-fundo (3,5 kHz) registrou camadas transparentes que indicam a presença de estratos sedimentares pouco consolidados, enquanto o deslocamento do eco registrado pela ecobatimetria nem sempre foi relacionado unicamente com a presença de lama fluida. Finalmente, os resultados apontaram que para projetos de engenharia costeira e com fins de navegação, o mapeamento da densidade fundo do mar em conjunto com levantamentos geofísicos é eficaz, além de destacar essa questão da delineação do limite superior da lama fluida.

Palavras-chave: geoacústica, lama fluida, Rio Amazonas.

\footnotetext{
1 Universidade Federal do Espírito Santo (UFES), Laboratório de Oceanografia Geológica (LabOGeo), Av. Fernando Ferrari 516, 29600-075 Vitória, ES, Brazil - E-mails: pedromenandro@gmail.com; alexcardosobastos@gmail.com; vdsquaresma@gmail.com

2Universidade Federal do Rio de Janeiro, COPPE, C203, 21945-970 Rio de Janeiro, RJ, Brazil - E-mail: susanavinzon@gmail.com
} 


\section{INTRODUCTION}

Sediment physical properties are known to be the main variables controlling how acoustic waves interact with the seabed, but different phases in sediment consolidation (including water and gas content) may also influence on acoustic behaviour (Hamilton \& Bachman, 1982; Lambert et al., 2002). Attempts to develop mathematical models that describe the behaviour of acoustic waves in sediments have been conducted for decades (Stoll, 1980). However, an effective, unified method to describe this process has been difficult to achieve due to the almost unlimited combinations of variables in different sediment types. Thus, several studies have been conducted to investigate the conversion of acoustic parameters on physical properties of sediments and geological interpretations (Hamilton \& Bachman, 1982; Lambert et al., 1993; Stevenson et al., 2002; Macedo et al., 2009; Ayres Neto et al., 2013), allowing the improvement of the seafloor acoustic mapping (Davis et al., 2002; Kim et al., 2004).

The technical advances of acoustic methods contribute to various human activities, from coastal engineering projects to the management of fishery resources (Kearey et al., 2009). In terms of coastal engineering application, the mapping of the seabed in areas with large accumulations of fine sediments represents an important scientific challenge regarding the applicability of different acoustic sources. In this scenario, we can point out the distinct acoustic signal response in areas characterized by the occurrence of fluid mud. Fluid mud can be described as a high concentrated sediment suspension with a density of up to $1200 \mathrm{~kg} / \mathrm{m}^{3}$ (McAnally et al., 2007). Detection and delineation of fluid mud layers are of great importance for the determination of nautical depths (navigability) and dredging projects (Wurpts, 2005; Fontein \& Byrd, 2007; Quaresma et al., 2011).

The detection of muddy deposits in high-resolution acoustic data is generally easy to accomplish. However, the acoustic response depends on the frequency used and the physical characteristics of the deposit. For high-frequency sub-bottom profiler data (2-20 kHz), for example, muddy deposits generally have a lower/free seismic reflection signature or are transparent due to the physical characteristics of the sediment (Garcia-Garcia et al., 2004). In dual frequency echo sounding (e.g. $50 \mathrm{kHz}$ and $210 \mathrm{kHz}$ ), muddy deposits can be registered with extended reflectors due to penetration, or are recognised by an echo signal displacement or double echo (Odhiambo \& Stephen, 2004). The displacement of the acoustic signal occurs when the highest frequency is reflected from the seabottom reflector, whereas the lower frequency penetrates the seafloor and is reflected from another subsurface sediment interface.
The case study developed here encompasses the geoacoustic identification of different bottom sediments types on the Amazon shelf. The Amazon shelf is considered critical for navigation (Fernandes, 2010), mainly due to the tidal range, the presence of thick layers of fluid mud and the mobility of sand banks on the inner shelf.

This work aims to contribute to the understanding and development of underwater geoacoustic through the investigation of high-resolution geophysical data, i.e., the analysis of different acoustic responses with respect to frequency and the physical sedimentary parameters (grain size and density), based on sedimentological data, bathymetric dual frequency and sub-bottom profiler data obtained on the inner shelf of the Amazon River.

\section{METHODOLOGY}

This study is based on a data set collected on the inner shelf near the mouth of the Amazon River North Channel. The dataset contains high-resolution geophysical records (dual-frequency echo bathymetry - $33 \mathrm{kHz}$ and $210 \mathrm{kHz}$ - and sub-bottom profiler data $-3.5 \mathrm{kHz}$ ), sedimentological analysis and in situ density measurements of surficial sediment.

The data were collected in June 2012, during a neap tide period, associated with an 11- to 15-m-deep coastal transect perpendicular to the coast, on the main shipping channel. Figure 1 shows the distribution of the 12 stations, with $10 \mathrm{~km}$ spacing, near the mouth of the Amazon River North Channel. The geophysical survey was carried out continuously, and at each station, sediment samples, in situ density data and suspended particulate matter data were collected.

\section{Geophysical Data}

The acoustic data were collected using three different frequencies: $3.5 \mathrm{kHz}, 33 \mathrm{kHz}$ and $210 \mathrm{kHz}$. The first is a high-resolution resonant source (a Stratabox sub-bottom profiler), and the other two were collected with a dual-frequency echo sounder (Syquest Bathy-500 DF) on the same profiles. The data were acquired continuously; however, the records presented here represent a pattern of each season.

The seismic records were displayed digitally in the Stratabox software, and the data from the dual-frequency echo sounding were interpreted in printed form.

The geoacoustic analysis was based on calculations of the reflection coefficients and attenuation values of the acoustic signal. With the acoustic impedance of different frequencies, it is possible to calculate the reflection coefficient of a particular sedimentary strata. This reflection coefficient (RC) represents the 
(a)

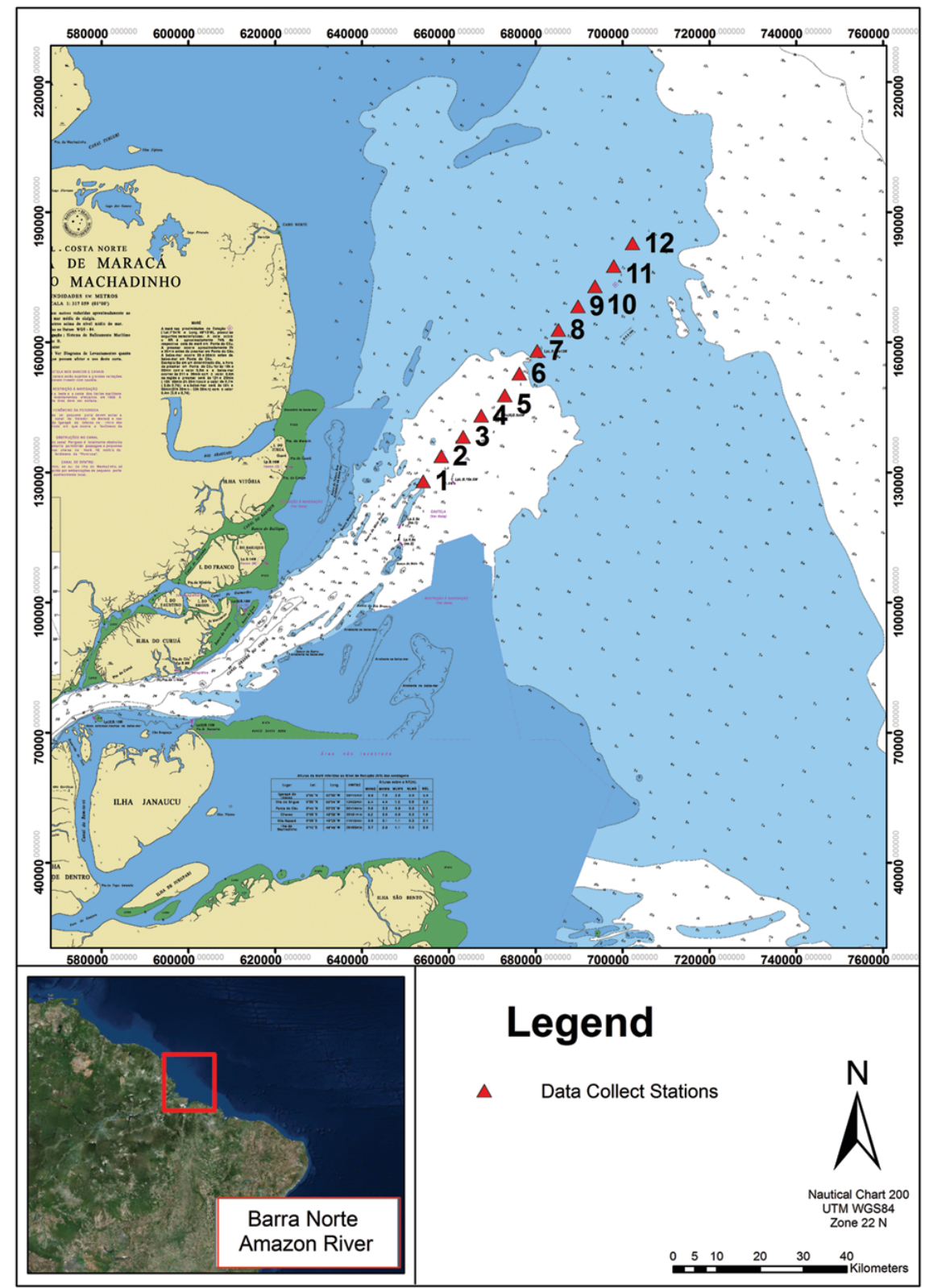

(b)

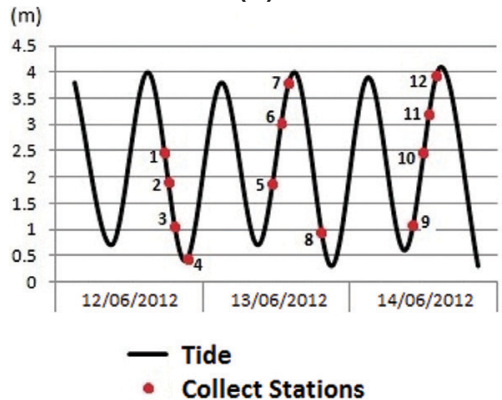

Figure 1 - a) Map of the study area with the 12 stations (Nautical Chart 200, Brazilian Navy). b) Data collections at each station located on a tidal curve (North Station Bar of the Amazon River - Ponta do Céu). 
amount of energy reflected as a function of various parameters of the sediment.

$$
R C=\frac{Z 2-Z 1}{Z 2+Z 1}
$$

where $R C$ is the reflection coefficient and $Z$ is the acoustic impedance of different means (water and sediment, for example), which results from the product of the sound velocity on the medium and the density of the medium. The typical sound velocity values found by Falcão \& Ayres Neto (2010) are used for each type of sediment, and these values were used to calculate the acoustic impedance.

The calculation of the signal attenuation was based on the study of Hamilton (1972), who proposed the following equation that relates the frequency and attenuation:

$$
a=k \cdot f^{n}
$$

where $k$ is a constant that depends on the sediment type and $n$ is an exponent of the frequency $(f)$.

\section{In situ Density Measurements}

Density measurements were performed at each station with a densimeter (Densitune Silt Density Probe - Stema Systems), which has a metallic sensor tuning fork that vibrates at a predetermined frequency. When inserted into sediment, the frequency changes depending on the density of the sediment. The frequency values in millivolts are converted to $\mathrm{g} / \mathrm{L}$.

The calibration of the densimeter was conducted in the laboratory using sediment samples collected during the campaign. For preparation of the calibration file, the samples were mixed to a volume of approximately $50 \mathrm{~L}$, so that the densimeter sensor (probe) could be inserted without direct contact with the container. Subsequently, $2 \mathrm{~L}$ of sample and $2 \mathrm{~L}$ of water were individually withdrawn and weighed. The density of the sediment was determined according to Eq. (3).

$$
\rho_{\text {sediment }}=\rho_{\text {water }} \cdot\left(\frac{P_{\text {sediment }}}{P_{\text {water }}}\right)
$$

where $\rho$ is the density and $P$ is the weight. With the gradual dilution of the sediment with fresh water, three groups were obtained: greater than $1300 \mathrm{~g} / \mathrm{L}$, between 1300 and $1070 \mathrm{~g} / \mathrm{L}$ and less than $1070 \mathrm{~g} / \mathrm{L}$. At each dilution step, a new sample of sediment was removed and weighed; its density was both calculated and measured directly with the sensor.

\section{Measurements of Suspended Particulate Matter Concentration}

The concentration of suspended particulate matter (SPM) was measured using the optical equipment 3A OBS (Campbell Scientific). The measuring principle of the equipment is based on the fact that the backscattering of light is directly proportional to the amount and size of suspended matter in a sample. The turbidity sensor equipment OBS $3 \mathrm{~A}$ provided values of turbidity in Nephelometric Turbidity Units (NTU). Thus, a more accurate correlation between the signal from the $\mathrm{OBS}$ and the concentration of SPM is necessary to calibrate the equipment.

\section{Surface Sediment}

At each station, surface sediment samples were collected with a drag sampler. The samples were processed in the laboratory, which involved processes such as laser particle size analysis (Mastersize 2000, Malvern Instruments) and the calculation of sediment density based on the wet and dry weights of the sample in a known volume (Amos \& Sutherland, 1994).

\section{Statistical Analysis}

In the software Primer, a non-metric multidimensional scaling - NMDS (Clarke, 1993) using the Bray-Curtis index was accomplished to identify the relationships of similarity between the sediment properties and the geophysical records.

This statistical approach consists of a spatial sorting technique which can be applied to various situations, and is calculated based on a matrix of similarity or dissimilarity (Clarke, 1993). The similarity coefficient of Bray-Curtis was applied to the matrix of variables for each station after normalization of values, in the statistical program PRIMER. The NMDS calculates the distortion or stress (standardized residual sum of squares), which measures how much the distances in the diagram are different from the original. Thus, a low value of this index indicates that the distances reflect well the original, which facilitates the understanding of the data compared to a matrix of similarities.

The variables involved in this analysis were as follows: maximum penetration reached by the sub-bottom profiler signal (3.5 kHz), average grain size, calculated density of the sediment in the laboratory and reflection coefficient of the surface sediment.

\section{RESULTS}

\section{Physical Characteristics of the Surface Sediment}

A transition from a sandy bottom to a muddy bottom and a decrease in the density of the superficial sediment (as determined in the laboratory) occurred between stations 2 and 3 (Table 1). 
Table 1 - Physical analysis of the surface sediment samples and acoustic attributes of geophysical records.

\begin{tabular}{|c|c|c|c|c|}
\hline Station & $\begin{array}{c}\text { Average } \\
\text { grain size }(\phi)\end{array}$ & $\begin{array}{c}\text { Calculated } \\
\text { density }\left(\mathrm{kg} / \mathrm{m}^{3}\right)\end{array}$ & $\begin{array}{c}\text { Reflection } \\
\text { coefficient }\end{array}$ & $\begin{array}{c}\text { Signal }(3.5 \mathrm{kHz}) \\
\text { penetration }(\mathrm{m})\end{array}$ \\
\hline 1 & 5.24 & 1847.67 & 0.3195 & 2.0 \\
2 & 3.47 & 1692.43 & 0.2795 & 2.0 \\
3 & 6.51 & 1526.73 & 0.2101 & 4.0 \\
4 & 7.12 & 1523.00 & 0.2089 & 4.0 \\
5 & 6.90 & 1483.26 & 0.1962 & 1.8 \\
6 & 6.98 & 1477.88 & 0.1945 & 4.0 \\
7 & 6.61 & 1553.27 & 0.2183 & 2.5 \\
8 & 6.02 & 1352.57 & 0.1515 & 3.0 \\
9 & 6.81 & 1358.25 & 0.1535 & 3.0 \\
10 & 6.64 & 1349.19 & 0.1503 & 2.5 \\
11 & 6.03 & 1525.30 & 0.2096 & 2.2 \\
12 & 6.20 & 1483.61 & 0.1963 & 2.0 \\
\hline
\end{tabular}

The fluid mud appeared only in the in situ densimeter probe data beginning at station 6, as shown in densimetric profiles (Fig. 2). It is important to highlight that the determination of the density of seabed sediments one must have undisturbed samples, and the samples collected from drag samplers are not undisturbed. Thus, the difference among the in situ density values and the calculated density values could be atributed to the collect method.

\section{Acoustic Signal}

The geophysical results indicate that a transition from a sandy to a muddy bottom occurs between stations 2 and 3 , both in the acoustic records (Table 2) and in the calculations of the reflection coefficient presented in Table 1 . As expected, higher reflection coefficients correlate with higher densities and larger grain size.

Based on the intensity of the reflection signal from the surface layers, the first two stations are distinguished from the others: the sub-bottom profiler recorded a stronger relatively superficial reflection (with a darker trace), and the two echo bathymetry frequencies did not detect different bottom reflectors, i.e., no echo displacement was present. The displacement of the echo - or double echo - occurs because the highest frequency reflects off of a shallow reflector that does not reflect the lower frequency, due to the acoustic response of the surficial low-density material. Therefore, the lower frequency penetrates farther and reflects off of a subsurface reflector. Hence, the same seafloor can be registered at different depths. In the case of the first two stations, neither echo displacement (Table 2, as seen in station 4) nor extended surface signal trace (Table 2, as seen in station 10) was observed. At the rest of the stations, the surface reflection was weaker (with transparent shallow sedimentary layers), as shown by the values of the reflection coefficient, allowing greater penetration of the acoustic signal and echo displacement of the signal in the echo sounder frequencies. This group (stations 3-12) can be subdivided into stations 3, 4, 5, 6 and 7, which exhibit a small range of reflection coefficient values and sedimentological characteristics; stations 8,9 and 10, which have very similar densities and reflection coefficients; and stations 11 and 12, which resemble stations 3-7 but have smaller grain sizes and a more marked presence of fluid mud, as recorded by the densimeter.

The data showed consistency between the records of the sub-bottom profiler and the echo bathymetry. Generally, in areas where the seismic reflection was stronger and the seismic signal penetration lower, no echo displacement occurred between the frequencies of the echo sounder.

\section{Statistical Analysis}

The physical properties of the sediment (average grain size and density) and acoustic parameters (reflection coefficient - RC and penetration of $3.5 \mathrm{kHz}$ signal) were investigated using the NMDS technique. In this study, the stress value obtained was 0.03 , which corresponds to a good ordering, ensuring a good reliability on the interpretation of results (Clarke \& Warwick, 2001).

According to the plot (Fig. 3), the density and the reflection coefficient are observed to be well correlated, because the density is part of the RC calculation. In addition, there is a trend of the smaller are the values of these variables, the greater the signal 

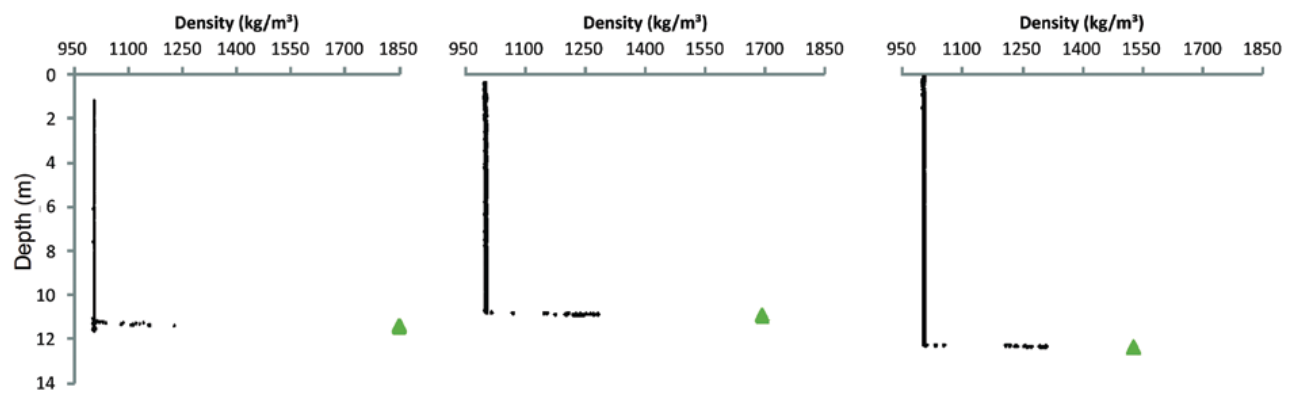

Density $\left(\mathrm{kg} / \mathrm{m}^{3}\right)$
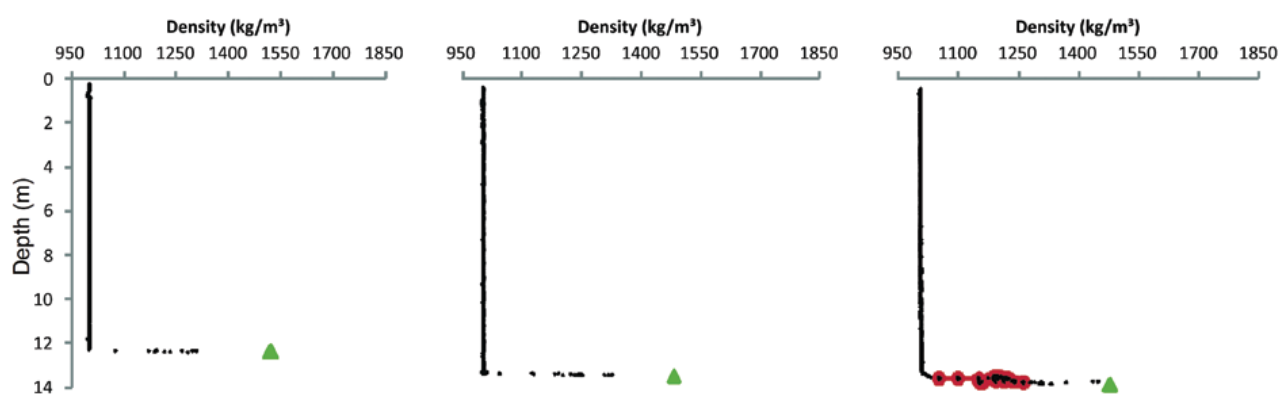

Density $\left(\mathbf{k g} / \mathrm{m}^{3}\right)$
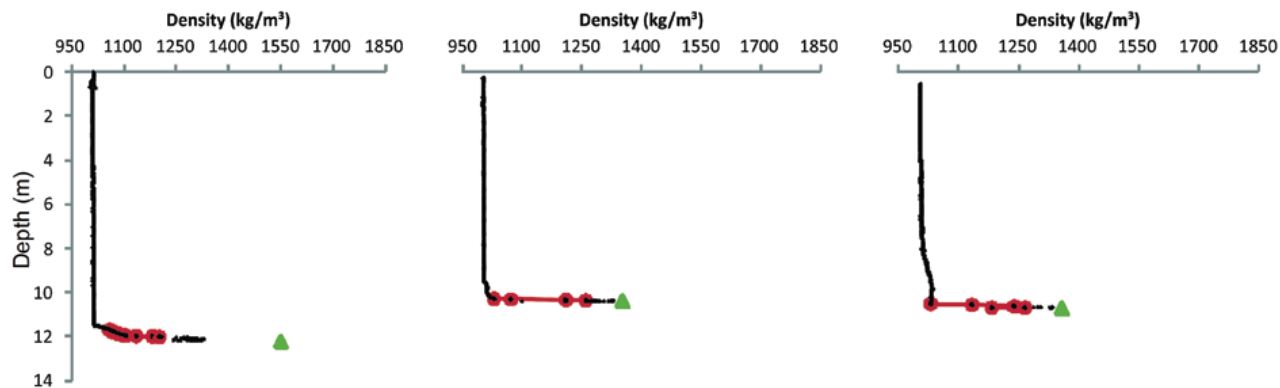

Density $\left(\mathrm{kg} / \mathrm{m}^{3}\right)$

Density $\left(\mathrm{kg} / \mathrm{m}^{3}\right)$
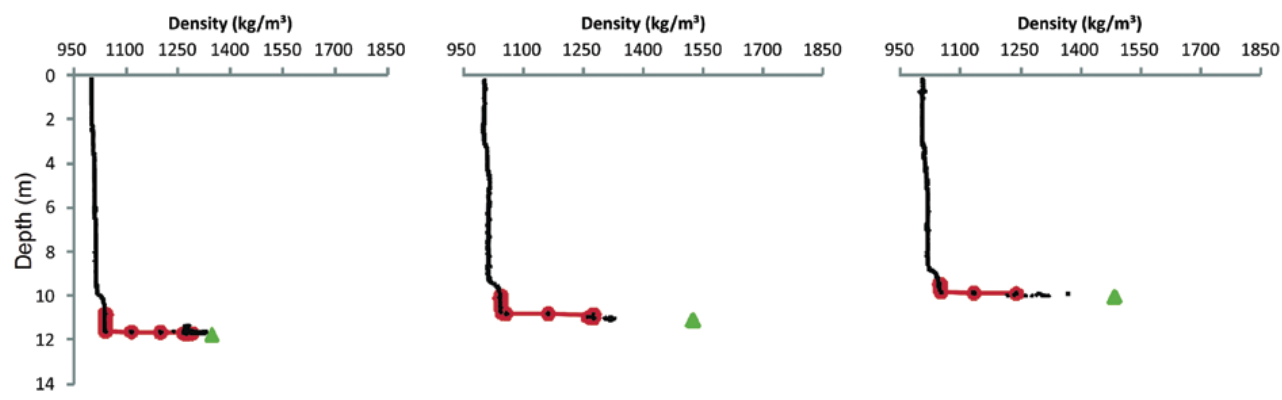

Figure 2 - In situ densimetry profiles (fluid mud in red circles) and laboratory calculated density values (green triangles).

penetration and the greater the grain size (finer on the phi scale). Thus, the signal penetration appears to be inversely correlated with the reflection coefficient because a higher reflection coefficient corresponds to greater reflection of energy from the seabed surface, resulting in less energy propagating into the sediment deposit.

The graph (Fig. 3) shows that the first two stations are somewhat separated from the others, corroborating interpretations initially made based on the geophysical records and the grain size analysis. This group is characterised by coarser grain sizes, low signal penetration and high-reflection coefficients. It is possible to distinguish some other groups, such as the stations 8,9 and 10. This group features the lowers densities values (ranging between 1349 and $1358 \mathrm{~kg} / \mathrm{m}^{3}$ ) and reflection coefficients (Table 1). The grouping of stations 3,4 and 6 is more associated with the axis of signal penetration, in which these stations showed the highest values of this variable. In addition, the grain size values of this group were, on average, higher compared to 
Table 2 - Geophysical data (echo bathymetry and sub-bottom profiler records).

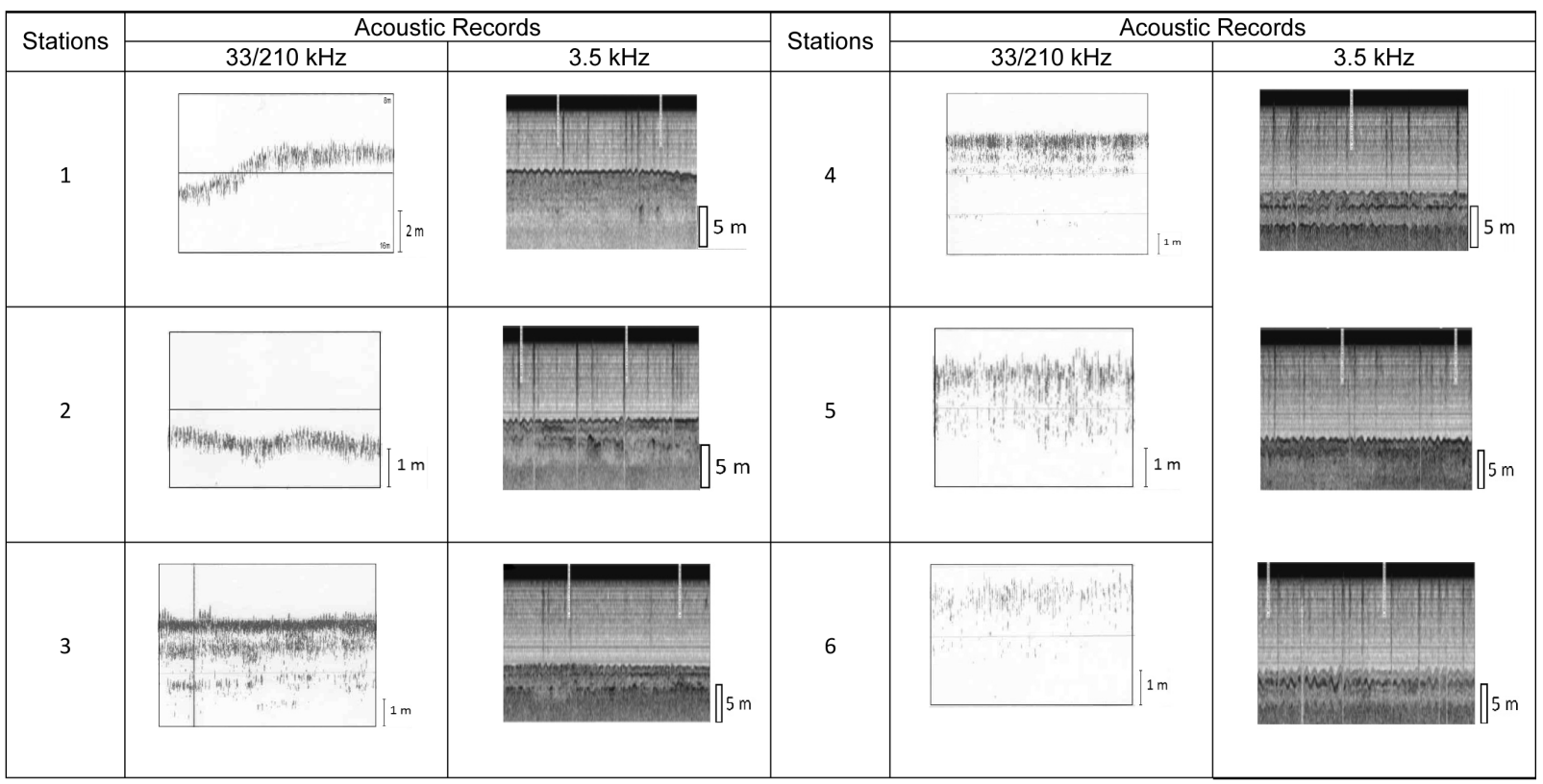

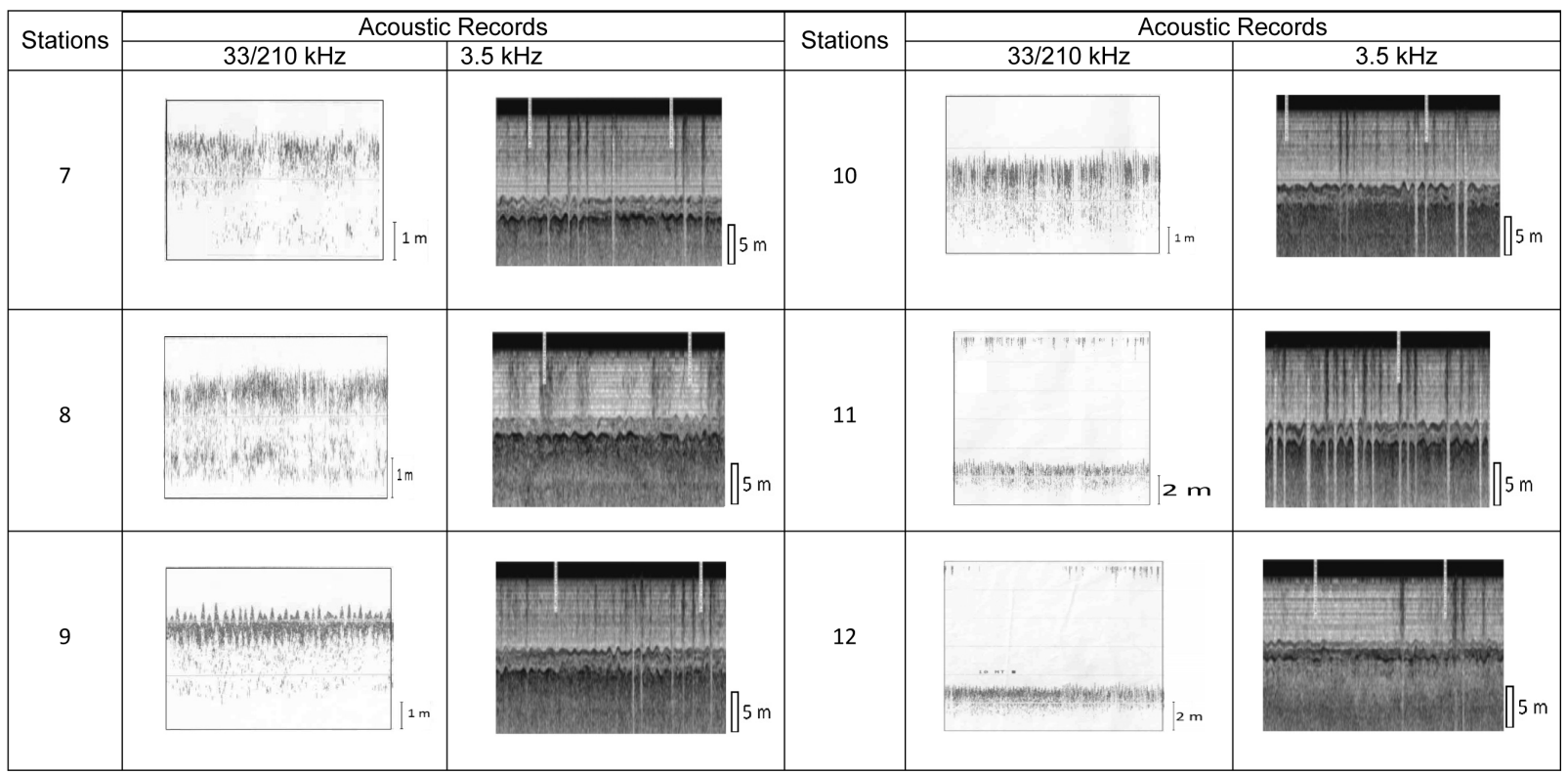

the other recognized groups. The last identified group includes stations 5, 7, 11 and 12, with similar characteristics of grain size and signal penetration.

\section{DISCUSSION}

The results of the physical characteristics of the sediment and recorded acoustic patterns presented here are consistent with the important work of Akal (1970), who observed the effects of physical properties on the sound wave reflections at various locations.
This author found a correlation between porosity and the reflection coefficient, noting that lower densities are associated with higher porosities, and weaker reflections. Baldwin et al. (1985) found higher correlations between acoustic impedance and density than between acoustic impedance and grain size, results that are similar to the data set presented here, including the statistical analysis.

According to Eq. (2) described above, the attenuation values should increase with increasing frequency, which is consistent 


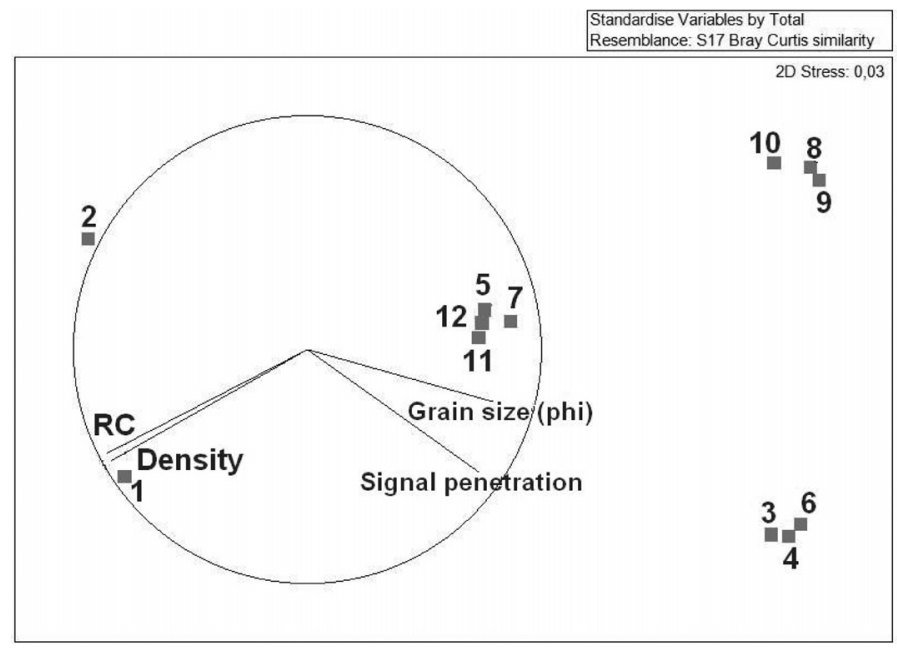

Figure 3 - Non-metric multidimensional scaling analysis showing the relationship among the parameters and the data collection stations.

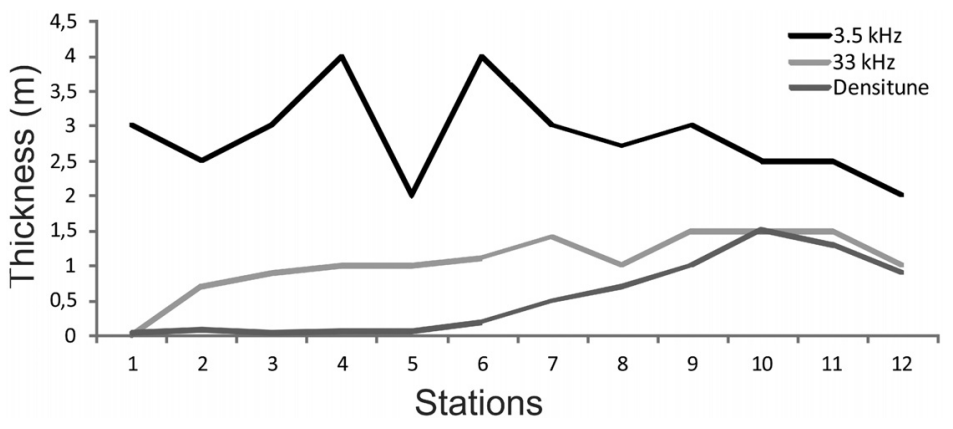

Figure 4 - Penetrations of $3.5 \mathrm{kHz}$ and $33 \mathrm{kHz}$ signals (bottom reflector is assumed to be detected by the frequency of $210 \mathrm{kHz}$ ) and the thickness of fluid mud layer measured by densimeter.

with the acoustic data presented and with other studies (Robb et al., 2006; Macedo et al., 2009). The sources used in the data survey emit pulses with the following power specifications: a) $160 \mathrm{~dB}$ for the $210 \mathrm{kHz}$ frequency; and b) $175 \mathrm{~dB}$ for frequencies of 33 and $3.5 \mathrm{kHz}$. The calculation of the attenuation rate using the values proposed by Hamilton (1972) for fine sediments (clayey silt) for the constant present in the equation, found the following values: i) $0.61 \mathrm{~dB} / \mathrm{m}$ for the frequency of $3.5 \mathrm{kHz}$; ii) $5.08 \mathrm{~dB} / \mathrm{m}$ for the frequency of $33 \mathrm{kHz}$; and iii) $28.94 \mathrm{db} / \mathrm{m}$ for the frequency of $210 \mathrm{kHz}$. These values are representative of a homogeneous deposit of clayey silt. Thus, these values do not account for the existing vertical internal variation in the surveyed sedimentary deposits, but are important to understand the observed relationship between signal penetration and frequency of the acoustic source in the records. The acoustic signal penetration was higher at lower frequencies (the wavelength pulse with the lowest resolution) and is also associated with lower sediment densities, which cause less signal attenuation at the surface. However, it should be noted that the internal features of a deposit are also critical to explaining the acoustic pulse attenuation. In the statistical analysis, the grain size was observed to be better correlated with the signal penetration than the density, although the relationship between the density and the signal penetration has indicated to greater penetrations in fine sediments. However, as discussed previously, the signal penetration can not only be associated with the surface properties of the sedimentary deposit.

Figure 4 presents the penetration at different frequencies. In this graph, the bottom reflector is assumed to be detected by the frequency of $210 \mathrm{kHz}$, because this is the methodology used in hydrographical surveys (PIANC, 1997). In addition to these data, the penetrations achieved by the $33 \mathrm{kHz}$ and $3.5 \mathrm{kHz}$ signals, and the thickness of the fluid mud layer (up to $1200 \mathrm{~kg} / \mathrm{m}^{3}$ ), as detected by the Densitune, are plotted. The data support the idea that the higher frequencies attenuate more quickly. In the case of the frequency of $3.5 \mathrm{kHz}$, the internal characteristics of the deposit were more influential on the process of attenua- 


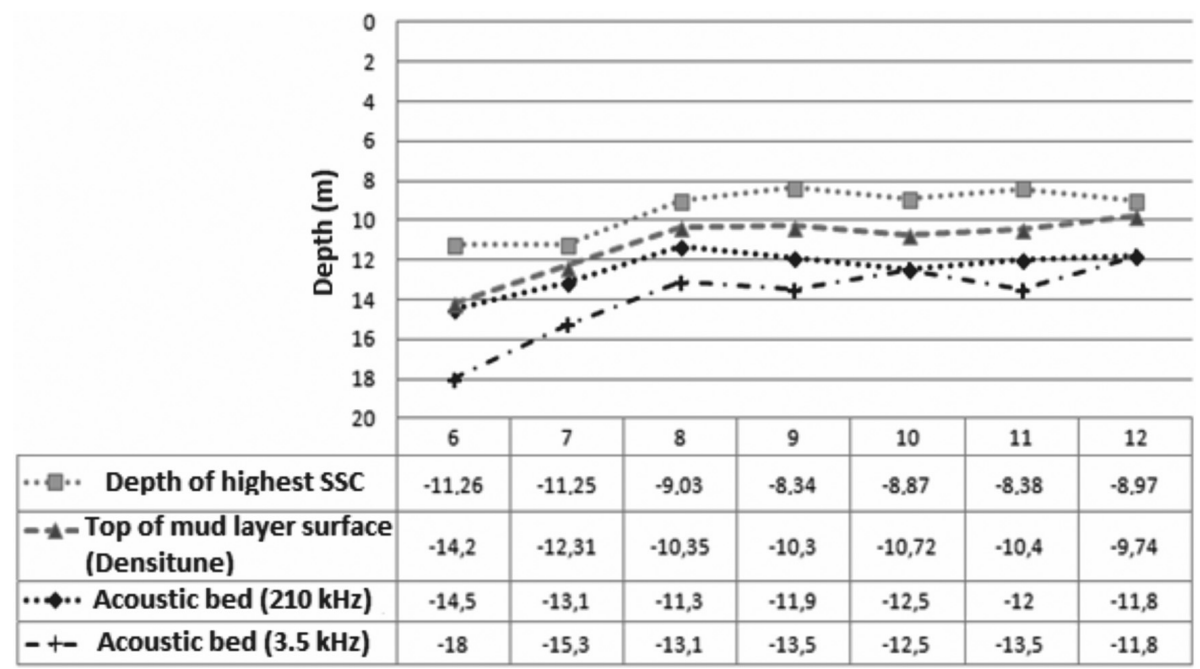

Figure 5 - Depths measured by the different methods at the stations with presence of fluid mud: acoustical depths ( $3.5 \mathrm{kHz}$ and $210 \mathrm{kHz}$ signals), depth of the top of fluid mud layer identified by densimetry, and the depth with highest suspended particulate matter - SPM (the upper limit of the equipment is $6.5 \mathrm{~g} / \mathrm{L}$ ).

tion than the surface sediment physical properties. This pattern differs from the pattern observed for the frequency of $33 \mathrm{kHz}$, which responded better to the surface characteristics because it has higher resolution.

In the analysis of sediments with different grain sizes, Macedo et al. (2009) found low values of attenuation in the fluid mud when compared with other types. The highest penetrations observed in our data set, which were found at stations where there is fluid mud, are consistent with the results of other studies (Kim et al., 2004; Macedo et al., 2009), as well as the Biot-Stoll theory, described by Stoll (1980) and reviewed by Akal (2001). This theory stipulates that sediments with a high concentration of water provide a movement almost in phase to where the wave stimulation occurs, a near absence of viscous dissipation speed, and a low attenuation.

Conventional acoustic records for seabed investigation usually fail to detect slight variations (such as ten or less decimal units of density), unless they pass through a series of processing steps. A comparison of the results presented in Figure 4 with the following graph (see Fig. 5) shows that the upper limit of the lutocline is not detected by any acoustic method frequency nor by the densimeter.

These results show the initial detection of the lutocline occurred only using optical methods (data from OBS-3A). The results also suggest that the bottom detection via the acoustic methods used in this study may be indicate a mobile fluid mud layer, depending on the frequency used, on top of the stationary fluid mud, or cohesive bed, which is more consolidated, according to the terms used by Ross \& Metha (1989).

The resolution and sensitivity of different frequency signals in the detection of changes in acoustic impedance explain the echo displacement. The reason certain echo sounder records feature a frequency-based echo displacement and other records feature more noise between the frequencies is complex and is likely related to the geotechnical parameters of the sedimentary deposit. A factor to consider is the consolidation of the muddy layer, which could be related to sediment dynamics. The graph in Figure $1 \mathrm{~b}$ shows no clear trend between the moment of collection (according to the tidal curve) and the presence of a clearer echo displacement. Stations 3, 4, 7 and 8 (Table 2) featured the clearest echo displacement and are locations where the data were collected at approximately slack tide, i.e., when the sediment dynamics are less intense and the settling of particles occurs, creating a denser suspension but lacking the time for the consolidation of the sediment.

Thus, it should be noted that the echo displacement (between the frequencies of $210 \mathrm{kHz}$ and $33 \mathrm{kHz}$ ) is not always the presence of fluid mud. The interpretation that this echo pattern represents fluid mud may generate errors related to navigation, such as the definition of nautical depth, and to coastal engineering projects, such as the measurement of dredging volumes using only the echo sounder (there is no need to dredge fluid mud because it poses no hazard to navigation). Fontein \& Byrd (2007) discuss the issue of maintenance of ports and note that rheological parameters should be considered for delimitation of nautical depth because the same density from different local materials have different resistances to shear. Schettini et al. (2010) found differences in the thickness of muddy packages investigated by these methods (echo bathymetry and densimetry), 


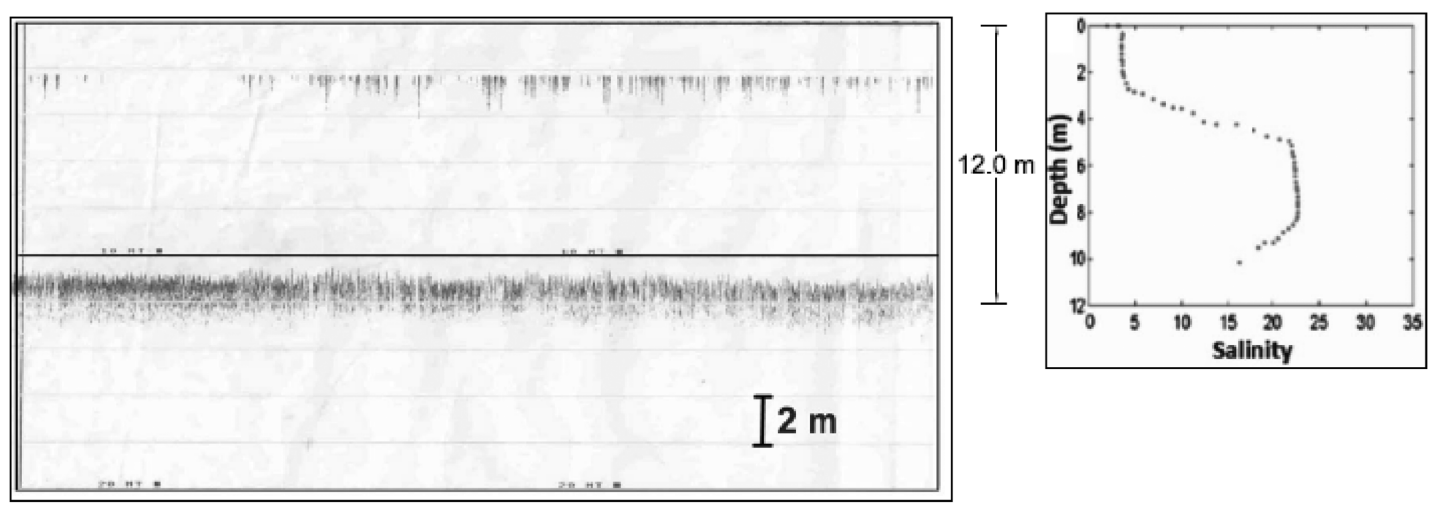

Figure 6 - Echo sounder record at $12 \mathrm{~m}$ depth indicating the presence of the halocline in the water column, and salinity profile in the water column.

noting that the thickness of mud mapped by echo sounder were more significant. Quaresma et al. (2011) also succeeded in mapping the thickness muddy layers in a port area through indirect and direct methods. The authors were also able to see the difference between the measured densities and the results provided by the acoustic method.

Lambert et al. (2002) studied the variation in the acoustic response signals $30 \mathrm{kHz}$ and $50 \mathrm{kHz}$, and found that higher frequencies were associated with higher ranges, i.e., the shortest wavelength detects minor variations in sedimentary deposit. A well-illustrated situation regarding this issue was the identification of the halocline with the frequency of $210 \mathrm{kHz}$ in the records of echo bathymetry (Fig. 6a) of the last four stations. Although the lutocline was not detected, the halocline appeared in the form of a noise recorded in the water column (between 2 and 3 meters) and seems to result from changes in salinity along the water column, which may indicate, with more acoustic studies involving these properties, a greater influence of salinity on the acoustic impedance than the suspended sediment. This type of result has already been studied by processing seismic data, as already shown in some studies (Holbrook et al., 2003; Ruddick et al., 2009), and suggest that in the future it may be possible to invert of seismic signal amplitudes to estimate the temperature of the ocean.

\section{CONCLUSION}

It was observed that different methodologies surveying the same area can yield completely different results. In the analyses, the frequency and physical properties were important in understanding the relationship between surface sediment and acoustic attributes such as reflection and signal penetration.

The stations where fluid mud (lowest surface density) was observed, reflections were weaker due to a lower acoustic impedance contrast, and the penetration of the acoustic wave was higher, in part due to the lower signal attenuation. It is also evident that for a better understanding of the relationship between these properties (signal penetration and sediment density) a more detailed stratigraphic study of the probed section would be necessary.

Statistical analysis was used as a tool to support the interpretations made from the geophysical records and the physical properties of the sediments, pointing the density as a determining variable for the interpretation of surface acoustic reflection. These findings indicate the effectiveness of mapping seabed density along geophysical surveys for use in navigation. The average grain size of the sediment was also influential in the statistics for the recognition of different sediment groups.

The recognition of the upper boundary of the fluid mud layer was only possible using optical methods, indicating that the acoustic methods used in this work, despite identifying the occurrence of this material, lack the requisite resolution for more detailed objectives. This result should serve as a serious warning with regard to the delimitation of fluid mud in port areas. However, it is important to highlight the observation of the halocline recorded in the echo sounding data because the difference in acoustic impedance between different salinities is very small.

More detailed studies involving other rheological properties within the stratigraphic column, such as plasticity limits may improve our understanding of the behaviour of acoustic signals.

\section{ACKNOWLEDGEMENTS}

This research was funded by a Capes/MEC/Brazil Research Grant Ciências do Mar 224/2010. The first author had a Capes postgraduate scholarship. 


\section{REFERENCES}

AKAL T. 1970. The relationship between those physical properties of underwater sediments that affect bottom reflection. SACLANT ASW Research Centre. Technical Report N. 177.

AKAL T. 2001. Acoustics in marine sediments. Encyclopedia of Ocean Sciences. Academic Press. p. 72-88.

AMOS CL \& SUTHERLAND T. 1994. A rapid technique for the determination of dry sediment mass from saturated marine sands. J. Sediment. Res., 64(3): 668-670.

AYRES NETO A, MENDES JNT, SOUZA MG, REDUSINO Jr M \& PONTES RLB. 2013. Geotechnical influence on the acoustic properties of marine sediments of the Santos Basin, Brazil. Mar. Georesources Geotechnol., 31(2): 125-136.

BALDWIN KC. 1985. An analysis of $3.5 \mathrm{kHz}$ acoustic reflections and sediment physical properties. Ocean Eng., 12(6): 475-492.

CLARKE KR. 1993. Non-parametric multivariate analyses of changes in community structure. Aust. J. Ecol., 18: 117-143.

CLARKE KR \& WARWICK RM. 2001. Change in marine communities: an approach to statistical analysis and interpretation. 2 ed., PRIMER-E: Plymouth. $176 \mathrm{pp}$.

DAVIS A, HAYNES R, BENNELL J \& HUWS D. 2002. Surficial seabed sediment properties derived from seismic profiler responses. Mar. Geol., 182: 209-223.

FALCÃO LC \& AYRES NETO A. 2010. Parâmetros físicos de sedimentos marinhos superficiais da região costeira de Caravelas, Sul da Bahia. Brazilian Journal of Geophysics, 28(2): 279-289.

FERNANDESRD. 2010. Formação e evolução dos bancos de areia da foz do rio Amazonas. PhD thesis, Universidade Federal do Rio de Janeiro, Brazil. $131 \mathrm{pp}$.

FONTEIN WF \& BYRD RW. 2007. The nautical depth approach, a review for implementation. In: WODCON XVIII Annual Dredging Seminar.

GARCÍA-GARCÍA A, GARCÍA-GIL S \& VILAS F. 2004. Echo Characters and recent sedimentary processes as indicated by high-resolution subbottom profiling in Ría de Vigo (NW Spain). Geo-Mar. Lett., 24: 32-45.

HAMILTON EL. 1972. Compressional-wave attenuation in marine sediments. Geophysics, 37(4): 620-646.

HAMILTON EL \& BACHMAN RT. 1982. Sound velocity and related properties of marine sediments. J. Acoust. Soc. Am., 72(6): 1891-1904.

HOLBROOK WS, PÁRAMO P, PEARSE S \& SCHMITT RW. 2003. Thermohaline Fine Structure in an Oceanographic Front from Seismic Reflection Profiling. Science, 301: 821-824.

KEAREY P, BROOKS M \& HILL I. 2009. Geofísica de Exploração. São Paulo: Oficina de Textos, Brazil. $438 \mathrm{pp}$.
KIM GY, RICHARDSON MD, BIBEE DL, KIM DC, WILKENS RH, SHIN SR \& SONG ST. 2004. Sediment types determination using acoustic techniques in the Northeastern Gulf of Mexico. Geosciences J., 8(1): 95-103.

LAMBERT DN, CRANFORD JC \& WALTER DJ. 1993. Development of a high resolution acoustic seafloor classification survey system. In: Proceedings of the Institute of Acoustics. Underwater Acoustics Group Conference, University of Bath.

LAMBERT DN, KALCIC MT \& FAAS RW. 2002. Variability in the acoustic response of shallow-water marine sediments determined by normalincident $30 \mathrm{kHz}$ and $50 \mathrm{kHz}$ sound. Mar. Geol., 182: 179-208.

MACEDO HC, FIGUEIREDO Jr AG \& MACHADO JC. 2009. Propriedades acústicas (velocidade de propagação e coeficiente de atenuação) de sedimentos marinhos coletados nas proximidades da llha do Cabo Frio, RJ. Brazilian Journal of Geophysics, 27(2): 195-204.

MCANALLY WH, ASCE F, FRIEDRICHS C, HAMILTON D, HAYTER E, SHRESTHA P, RODRIGUEZ H, SHEREMET A \& TEETER A. 2007. Management of fluid mud in estuaries, bays, and lakes. I: Present state of understanding on character and behavior. J. Hydraul. Eng., 133(1): 9-22.

ODHIAMBO BK \& STEPHEN KB. 2004. Integrated Echo Sounder, GPS, and GIS for Reservoir Sedimentation Studies: Examples from Two Arkansas Lakes. Journal of the American Water Resources Association (JAWRA), 40(4): 981-997.

PIANC. 1997. Approach Channels: A Guide for Design. Report of Working Group No. 30 of the Permanent Technical Committee II, Supplement to Bulletin No. 9. Brussels: General Secretariat of the Permanent International Association of Navigation Congresses.

QUARESMA VS, BASTOS AC, LOUREIRO DV \& PAIXÃO S. 2011. Utilização de métodos geofísicos para mapeamento de lama fluida no Porto de Tubarão, Vitória (ES-Brasil). Brazilian Journal of Geophysics, 29(3): 487-496.

ROBB GBN, BEST AI, DIX JK, BULL JM, LEIGHTON TG \& WHITE PR. 2006. The frequency dependence of compressional wave velocity and attenuation coefficient of intertidal marine sediments. J. Acoust. Soc. Am., 120(5): 2526-2537.

ROSS MA \& METHA AJ. 1989. On the mechanics of lutoclines and fluid mud. J. Coastal Res., Spec. Issue, 5: 51-61.

RUDDICK B, SONG H, DONG C \& PINHEIRO L. 2009. Water Column Seismic Images as Maps of Temperature gradient. Oceanography, 22(1): 192-205.

SCHETTINI CAF, ALMEIDA DC, SIEGLE E \& ALENCAR ACB. 2010. A snapshot of suspended sediment and fluid mud occurrence in a mixedenergy embayment, Tijucas Bay, Brazil. Geo-Mar. Lett., 30: 47-62.

STEVENSON IR, McCANN C \& RUNCIMAN PB. 2002. An attenuationbased sediment classification technique using Chirp sub-bottom 
profiler data and laboratory acoustic analysis. Mar. Geophys. Res., 23: 277-298.

STOLL RD. 1980. Theoretical aspects of sound transmission in sediments. J. Acoust. Soc. Am., 68(5): 1341-1350.
WILKS DS. 2006. Statistical Methods in the Atmospheric Sciences. 2nd ed., International Geophysics Series, v. 59, Academic Press.

WURPTS R. 2005. 15 Years Experience with Fluid Mud: Definition of the Nautical Bottom with Rheological Parameters. Terra et Aqua, 99: 22-32.

Recebido em 30 abril, 2015 / Aceito em 13 novembro, 2015

Received on April 30, 2015 / Accepted on November 13, 2015

\section{NOTES ABOUT THE AUTHORS}

Pedro Smith Menandro. Graduated in Oceanography and obtained M.Sc. in Environmental Oceanography at the Universidade Federal do Espírito Santo (2014). Currently, is a Ph.D. student in Environmental Oceanography at the Universidade Federal do Espirito Santo. Works in the Geological Oceanography field with emphasis on hydrographic surveys (multibeam data), geoacoustics and applied high-resolution geophysics.

Alex Cardoso Bastos. Holds a Geology degree from the Universidade Federal do Rio de Janeiro (1993), M.Sc. in Marine Geology and Geophysics from the Universidade Federal Fluminense (1997) and Ph.D. in Sedimentary Dynamics, University of Southampton (2002). Currently, works as an Associate Professor at the Universidade Federal do Espírito Santo and was granted a productivity scholarship from CNPq level II. Is a faculty member of the Post-graduate Program on Environmental Oceanography (UFES). Works in Geological Oceanography with emphasis on Geophysics and Marine Sedimentation.

Valéria da Silva Quaresma. Graduated in Geography from the Universidade Federal Fluminense (1992), obtained M.Sc. in Marine Geology and Geophysics from the Laboratory of Marine Geology (UFF, 1997), and holds a Ph.D. in Geological Oceanography from the University of Southampton (2004). Since 2006 works as a Professor at the Universidade Federal do Espirito Santo as part of the faculty of the Post-graduate Program on Environmental Oceanography (UFES). Works in the field of sediment dynamics and applied high-resolution geophysics.

Susana Beatriz Vinzón. Graduated in Water Resources Engineering from the Universidad Nacional del Litoral, Master's and Doctorate in Ocean Engineering at the Universidade Federal do Rio de Janeiro. Currently, Adjunct Professor at the Universidade Federal do Rio de Janeiro working in the field of oceanography. Including research on dynamics of cohesive sediments, environmental modeling, sediment transport, tidal propagation, hydrodynamic modeling, numerical modelling and fine sediments. 